\title{
Expectation and Anticipation of Dynamic Visual Events by 3.5-Month-Old Babies
}

\author{
Marshall M. Haith, Cindy Hazan, and Gal S Goodman
}

Untuersty of Denuer

\begin{abstract}
Haith, Mahshall M, Hazan, Cindy and Goodva\, Gall S Expcctation and Anticipation of

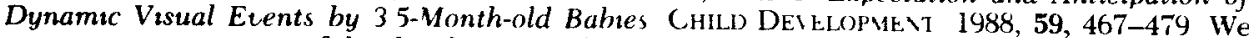
report an investagation of the development of visual expectancies in 35-month-old infants One of the infant $s$ eyes was videorecorded as the intant $w$ atched $d$ senes of slides that were presented noncontangent on behavior Babies were presented an altemating and an irregular series of 30 slides with a 700-msec onset duration separated br an interstimulus inten al (ISI) The ISI for the alternating series was $1,100 \mathrm{msec}$, whereas the slides for the irregular senes were separated bv $900,1,100$, or $1,300 \mathrm{msec}$, randomlv ordered One-half of the babies saw the irregular senes first, and one-half saw the regular senes first Babies in both groups provided evidence that ther developed expectatons for the visual events in the alternating senes Their reaction times (RTs) declined significantlv from 3-5 ' baseline' presentations, and their RT, were reliabl, faster dunng the altemating than the irregular senes Additionally, babies in the alternating-late group had sigmificantl more stimulus anticipations during the alternating than dunng the iregular scnes These findings indicate that 35 month-olds can detect regulant in a spatiotempord series, will develop expectancies for events in the senes, and will act on the basis of those expectancies even when those actions have no effect on the stumulus events We believe that infants are motivated to develop expectations for noncontrollable spatiotemporal events, because these expectations permit them to bring their visual behavior under partial intemal control
\end{abstract}

There is strong current interest in developing a theory of infant cognition that will easily relate to theories of later cognitive functioning An important characteristic of cognitive/perceptual theones in childhood and adulthood is concem for future-onented mental processes such as expectations for environmental events and planning of selfdirected activities Modern charactenzations of cognitive functioning, such as schema and frame theory, emphasize the role of expectaton for spatal lavouts and event sequences in facilitating a person's ongoing understanding of and memory for expenence (Minsky, 1975, Schank \& Abelson, 1977) as well as his or her scanning of scenes (Fnedman, 1979, Goodman, Price, Cohen, \& Hath, 1981) and recog- nition of items in these scenes (Fredman, 1979, Goodman, 1980)

However the study of future-onented actuvities in early infancv has been virtuallv ig. nored Research and conceptualization concerning perceptual/cognitive processes in early infance have traditionall focused on how the infant deals with currently avalable visual events, whether these events are new or familiar In a sense, then, the time frames of interest have been the present and the past Hebb's (1949) theoretical discussion over 3 decades ago of the role of expectancies in early infancy still stands as the onl systematic treatment and enjors only scattered empincal buttressing ${ }^{1}$

This research was supported bv research grants from NIMH (MH23412) and from VICHD (HD20026) to $\mathrm{MM} \mathrm{H}$ and was carned out while $\mathbf{M ~ M ~ H}$ was supported br a NIMH Research Scientist Award (MH00367) We thank Janette Benson, Rob Roberts, Naom Wentworth, and Michael McCarty for their helpful comments on drafts of this paper Tncia Botacell, Sandi Pipp Deborah Porter, and Mary Ann Goodwvn were involved in the formative stages of this research and have our appreciation An earlier version of this report was presented at the meetings of the International Conference on Infant Studies, New York, Apnl 1984 Requests for repnnts should be sent to Marshall M Haith, Department of Psvchologv Universit of Denver, 2040 S York Street Denver, CO 80208

${ }^{1}$ Kagan (1970) developed a mothvational theory of attention and cognitive development around the notion of "violation of expectancv" or discrepancy For Kagan, the concept refers to a structural schema of the object and an input match or mismatch In most cases the input is unchanging Thus Kagan s principal concern has been $w 1$ th the development of cognitive representations of objects rather than with how expectations contribute to the perceptual organization of the changing or dynamic events that concern us here

[Child Development, 1988, 59, 467-479 C 1988 by the Societ for Research in Child Development Inc

All nghts reserved 0009-3920/88/5902-0004\$01 00] 
Perhaps progress in studying expectatons in early infancy has suffered partly from the absence of a suitable paradigm We will introduce a new approach to studying infant expectations and will present findings that demonstrate that young infants develop visual expectations rapidly and tend to organize their behavior around these expectations

Before proceeding, it may be useful to present vanous usages of the term "expectaton" so that we can clanfy what we will be discussing Use of the term br theonsts has run the gamut from highly cognitive processes to relatively low-level sensonmotor processes At one extreme, for example, we speak of the expectation one person has for another's behavior in a social interaction (Markman, 1981) At the other extreme, we speak of the expectation a person has for the perceptual consequences of a motor command to move the eye (Helmholtz, 1925) The tume doman of interest may be relatively short (as in the expectation for retinal stamulus change consequent to an eye movement) or relatively long (as when one expects course work to lead to a degree) Expectations may refer to psychological processes utilized in static or dynamic situations For example, we expect that objects will occupy particular locations in familiar static scenes (Biederman, Glass, \& Stacy, 1973), and we expect that unimpeded moving objects will contnue to move (Aslın, 1981) Finally, expectations may be involved in situations in which a person's action is irrelevant (the onset of a rainstorm), interactive (moving the hand to catch a ball), or the only matter of concern (the consequence of a motor command to move the arm) What all of these examples share is allusion to a psychological process or processes which is (are) future onented We know of no theory that deals with all of these different types of expectancies Whether they involve similar or distunct processes is unknown Speculation about a sequence of development of vanous kinds of expectancies and their independence or interrelation could prove quite interesting It is essential, however, that we first develop a data base on future-onented processes in early infancy

For this presentation, we are interested in perceptual expectations that are relatively short-term in nature, that involve dynamic events, and that reflect an interaction between organismic action and environmental change It seems likely that the earliest expectations would be more perceptual than cognitive in nature, would involve relatively limited tume frames, and would depend on sensonmotor actions In contrast to traditional learning studies, the events we use are presented noncontingent on the infant's action We believe that babies must develop expectatons in order to deal with the dynamic flow of perceptual events in their environment, over which they often have no control, and that this class of expectations is among the earliest to occur

We want to present some terminology for discussing future-onented processes in order to distinguish our references to internal constructs from behavioral indices of those constructs The literature on expectancy and planning often fals to make this distunction The term "expectation" will be used as a cognitive/perceptual construct that refers to the infant's forecasting of a future event, the presence of an expectation will be indexed, behaviorally, by anticipation and response facilıtation

"Anticipation" will refer to an action that is initiated pnor to an event and is adaptive for it "Facilitation" will refer to enhancement of behavior after the actual event occurs (when, of course, there was no anticipation) As an illustration, consider a visual twochoice, reaction-tıme (RT) task A subject must move the eyes to the left or nght as rapidly as possible, when a corresponding left or nght light goes on Sometimes, a warning light flashes red or green first to indicate, respectively, that the left or nght response will be relevant for that tnal We know that the eye-movement response to the stmulus-light onset will be faster on trals preceded by the waming light Thus, the warning light "facilltates" the reaction, and we would infer that the facilitation reflects the presence of an expectation If the response actually occurred pnor to the onset of the left or nght light, we would say the response was "anticipatory," and we would also infer that an expectation had mediated the reaction Even though an anticipation would be in error for this task, there are related situations, such as the one we will describe, for which anticipation is quite appropnate

A few studies that are relevant to this example have been conducted on young infants, such as Aslin's careful observations of visual tracking in 10-week-old infants (Aslin, 1981) Aslin confirmed earlier reports that, pnor to 10 weeks, infants typically track a moving object with jerky eye movements, repeatedly losing and then refixating the object through its flight After 10 weeks, infants become increasingly able to track the object smoothly Aslin speculated that, in part, the infant's 
newfound ability might reflect the formation of expectations about the objects' continuing path Because eye-movement latencies to the appearance of a visual target exceed 200 msec, ad hoc reactions to the object's new locatons would generate a jerky rather than a smooth-trackıng performance Haith, Kessen, and Collins (1969) presented to 2- and 4month-old infants displays of sequentially 1 lluminated lights and reported that the infants appeared to make erroneous fixations that reflected the infants' expectation that events would continue to follow a linear trajectory rather than to change direction Similarly, Nelson (1968) reported that infants, ranging in age from about 15 to 4 months, contnued to move their eyes along a trajectory created by sequential illumination of discrete lights, even when intermediate onsets were deleted As another example, Anglin and MundyCastle (1969) presented infants from a few weeks to 8 months of age stimul that alternately appeared in nght and left windows, separated by $35 \mathrm{sec}$, they reported anticipatory fixations dunng this delay interval Unfortunately, the latter two reports did not provide comparative performance data dunng an unpredictable senes, as we shall see, one can obtain behavior durng a nonpredictable senes that looks like anticipation and must be taken into account in inferring that an expectation has been established We know of no reports suggesting that expectations may facilitate infants' reactions to stamuli by enhancing their response time

The purpose of the present study was to establish whether 35-month-olds could form expectations for a senes of predictable visual events that unfolded independent of their behavior We examined both anticipatory fixations and faclitated reactions to these events to provide evidence for the presence of expectations and compared these behaviors for relatively predictable and relatively unpredictable senes

\section{Method}

Overview - Each infant saw a sequence of projected slides that appeared to the left or nght of visual center The pictures moved up and down while they were on $(700 \mathrm{msec})$ For the alternating senes, successive slides were separated by an interval of $1,100 \mathrm{msec}$ and appeared in left-right alternation For the irregular senes, slides were separated by ISIs (interstimulus intervals) of $900,1,100$, or 1,300 msec, arranged randomly The image of the baby's nght eye was videotaped dunng this procedure We were especially interested to determine whether babies would detect the spatial and temporal predictability of the senes and whether they would manifest this detection through anticipatory eye movements and enhanced reaction times to slide onsets

Subjects - Twelve 35-month-olds participated in this experiment (range 3 months, 8 days to 3 months, 19 days) Data from 10 other babies were not used because we encountered equipment problems $(N=2)$, insufficient data were obtained $(N=4)$, or the baby was inattentive $(N=2)$, had an abnormal ins $(N=2)$, or made excessive shifts between stimulus locations during the ISI for both conditions ( $>65 \%, N=1$ )

Stımulı - The stumulı were 60 projected $35 \mathrm{~mm}$ slides of checkerboards, bull's eyes, and schematic faces in vanous combinations of green, red, yellow, black, and white The baby viewed the projected slides bv mirror reflection on a rear-projection screen that was $7 \mathrm{~cm}$ high $\times 152 \mathrm{~cm}$ wide, at a distance of $381 \mathrm{~cm}$ The stmulı were approximately $45^{\circ}$ square and their centers were $57^{\circ}$ to the left or nght of the infant's visual center Each stumulus moved vertically at a rate of $44 \%$ sec, completıng one up-down cycle for each presentation, which lasted $700 \mathrm{msec}$ The variations in stimulus objects and colors were combined with stimulus motion to maximize the infant's interest

Apparatus - The infant lav supine on a baby mattress and viewed the rear-projected stimul by reflection from a visible-reflecting, infrared-transmitting mirror (mirror $Y$ in $F_{1}$ g 1, Libby-Owens No 956) The image of the infant's right eye (in a camera field approximately $38 \mathrm{~cm}$ square) was videotaped by a TV camera that was equipped with an infrared video tube Light for televising this eye image was provided by an infrared source and collimator whose beam reflected from infrared-transmitting, visıble-reflectıng mirror $Z$ (Fig 1, Libby-Owens No 956), which was in the same optical path as the recording video camera The eye image was transmitted through mirrors $Y$ and $Z$ and reflected from front-surface mirror $X$ to the camera The collimator was fitted with optical filters (Corning 7-69, and Kodak Wratten 87c) to eliminate heat and to reduce visibility, because the collimated beam was directed toward infraredtransmitting mirror $Z$, only a small fraction of the light was reflected toward the infant's eye, from the infant's position, the light was virtually invisible This arrangement maximized the amount of light, reflected from the eye, that reached the $T V$ camera (because 


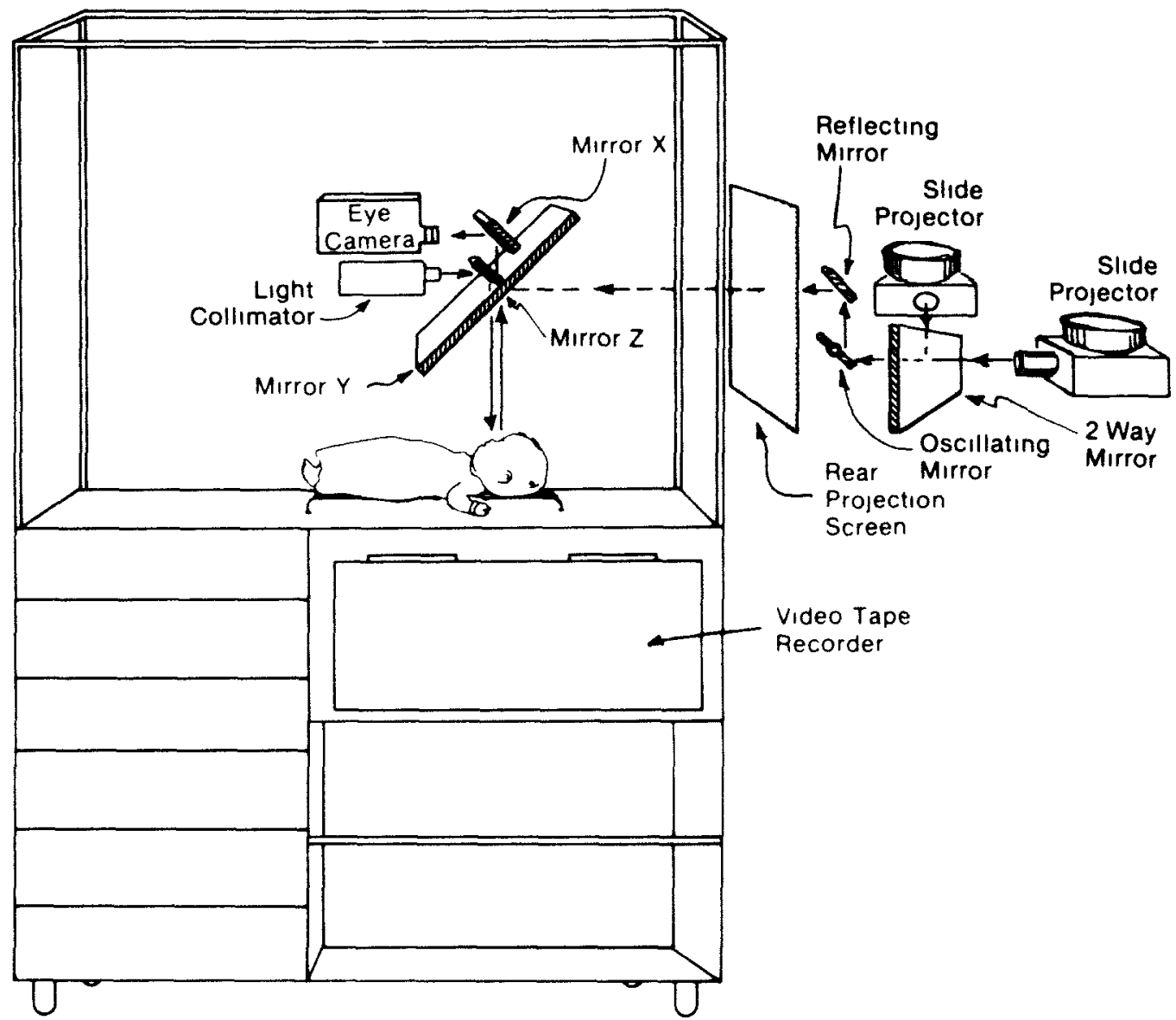

FIG 1 -Portraval of the recording and stmulus-presentation arrangement used in the expectancy studies Stamul were presented by the two projectors through computer-controlled tachistoscopic shutters The beam from one projector reflected from a tu o-way mirror, and the beam from the other was transmitted through the two-way mirror Both beams reflected from an oscillating mirror and a first-surface reflecting mirror before forming an image on the projection screen One projector presented stimuli positioned on the nght, and the other presented stimuli positioned on the left The infant viewed the stimuli by reflection from mirror $Y$ An infrared collimator illuminated the babv's eye by refiection from miror $Z$ and transmission through mirror $Y$ The image of the baby's eye was recorded by the infrared TV camera after passing through mirrors $Y$ and $Z$ and reflecting from mirror $X$

mirrors $Y$ and $Z$ were infrared-transmitting in the eye-camera path) while preserving the optical alignment of the beam and camera This optical alignment created an image of a "back-lit pupıl," produced by hight reflected from the retna back through the pupl The video recording of this white pupil against the dark ins facilitated the expenmenter's task in detecting eye movements, part of the source light was also reflected from the corneal surface of the eye and formed a small, bnght, white spot that served as a reference point for the center of the visual field The eye image was combined with the output of a video time/date generator, which provided time increments of $1 / 10 \mathrm{sec}$ for video recording
Two slide projectors were used to present the left and nght stımul These projectors were equipped with Lafayette tachistoscopic shutters The beam from one projector reflected from a two-way mirror angled at $45^{\circ}$, while that of the other passed through it To produce vertical motion of the projected stimul, beams from these projectors were further intercepted by a small mirror that oscillated around its horizontal axis, dnven by a small stepping motor (General Scanning drive and motors) In turn, the stepping motor was activated by a sine-wave output from a Heathkit Function Generator (IG1271), the resulting images oscillated vertically and smoothly, moving the image up and down a distance of 
$\pm 15^{\circ}$ during the $700-$ msec presentation of each stumulus

Through relays on a parallel $\mathrm{I} / \mathrm{O}$ buffer, a PDP 11/04 computer controlled the advance of the slide projectors and the timing of stimulus presentation through the tachistoscopic shutters The computer also controlled the presentation of one digit on the time/date recorder that was synchronized with the opening of the T-scope shutters, this digit displayed a " $l$ " when the left stimulus appeared, and a " 2 " when the night stumulus appeared

Procedure - The infant was placed supine on an infant seat, positioned so that his or her head rested in a cloth sling, which tended to restrain head movement A pacifier was offered to the infant as the TV eye camera was focused, and minor adjustments of the infant's head were made Dunng this time, both the left and nght stimul were shown continuously to hold the infant's interest When focus and positioning were established, the expenment began

Each baby saw 60 events, 30 of these appeared in a left-right alternating sequence, with an onset duration of $700 \mathrm{msec}$ The ISI for this alternating senes was $1,100 \mathrm{msec}$ The remaining 30 events appeared in an irregular spatal sequence, randomly ordered within the constraints that no more than three successive shides appeared on the same side, and the number of slides appeanng on each side was equal across each of the three 10-trial blocks The ISIs for this sequence varied among the values of $900,1,100$, or $1,300 \mathrm{msec}$ randomly sequenced, but balanced for frequency of occurrence Thus, the duration of both senes was $1069 \mathrm{sec}$ The vanable ISIs were used to augment the unpredictability of the irregular senes These two senes were presented to six of the babies in an alternating-irregular sequence (alternating-early) and to the remaining six in an irregular-alternating senes (alternating-late)

Data reduction - One measure of interest was the latency of imitiation of an appropnate eye movement following the onset of each slide that changed location (For the irregular senes, some slide onsets did not change location ) A second measure of interest was the frequency of shifts in fixation locaton durnng the anticipation interval (defined below) An observer played back the videotape on a Sony AVC-3650 at the slowest playback speed, this was calibrated on our machine to be a ratio of 1157 real time to playback tme The observer pressed a button to start an electronic clock when the stimulus digit on the time/date display appeared and pressed a button to stop the clock when the eye began to move, if the eye moved to the opposite side during the ISI preceding a slide onset, this procedure was reversed The clock provided a resolution of $1 / 10 \mathrm{sec}$, and a simple division of 157 recovered the estimated onglnal latency of the eye movement

Because the time sequence of event presentation was fixed, the scorer could not be uninformed about event onset, nor was it practical to keep the scorer blind about event location However, the correctness of the $\mathrm{d}_{\mathrm{l}}$ rection of eye movement, well over $95 \%$ in any case, was not our concern, rather, latencr was Given our optical setup and the expanded image of the eve, refixations were quite easily discerned We estimated that our procedure established the actual latency within $\pm 167 \mathrm{msec}$ This estimate was based on the fact that each video field, consuming $167 \mathrm{msec}$ in real time, occupied $262 \mathrm{msec}$ in playback time Although some lag was produced by the scorer's RT to respond to the event-onset signal and to the initiation of an eye movement, these RTs should have cancelled one another, leaving only the variance in RT as potential error This variability is typically around $50 \mathrm{msec}$, one-fifth of the 262 msec for a play back field or for the $167-\mathrm{msec}$ real-tıme estımate we used One subject's complete record was rescored by an expenenced scorer after an interval of several weeks The estumated RT values corresponded between $\pm 127 \mathrm{msec}$ (real time) for $67 \%$ of the events and $\pm 191 \mathrm{msec}$ for $88 \%$ of the events

\section{Results}

Mixed-model analyses of variance (ANOVAs) were carned out on the variables that will be reported, followed up by orthogonal comparisons for predicted differences Except where noted, type (alternating or irregular) and sequence (alternatung-early or alternatung-late) were the main effects, with type as a within-subject variable and sequence as a between-subject vanable in the 2 $\times 2$ ANOVAs

Anticipation results - We predicted that infants would detect the spatiotemporal rule that governed the appearance of the shides in the alternating series and would develop expectations for their appearances One index of these expectations is an anticipatory eye movement to the location of the next slide

In defining anticipatory eye movements, there was no doubt about eye movements that 


\section{Child Development}

changed sides pnor to event onset However, because a response to stmulus onset takes time, it is possible that an eye movement that occurs soon after stumulus onset could be anticipatory, that is, if it begins earlier than the lower limit on RT An eye movement that occurs earlier than this lower limit, by inference, reflects a motor command that occurred prior to stimulus onset and should be considered an anticipation

The postonset limit for the anticipation interval was set at $200 \mathrm{msec}$, that is, appropnately directed eye movements that began pnor to $200 \mathrm{msec}$ after strmulus onset were considered anticipatory, and those occurnng after 200 msec were considered event reactons Unfortunately, this decision had no direct data base, because we know of no published data on RTs for eye movements in 35month-old infants However, several studies in the literature report that when adults are presented peripheral stımuls more than $4^{\circ}$ from the current fixation point, their fastest RT is in the range of $180-200 \mathrm{msec}$ (e g , Becker, 1972, Saslow, 1967) We confirmed these observations for our situation with two adults who lay in the apparatus, saw the senes presented to the infants, and tred to respond to each event as rapidly as possible Their median RT was $255 \mathrm{msec}$ and their fastest RT was $196 \mathrm{msec}$ We know of no evidence that 35 -month-old babies have faster RTs than adults, in fact, the evidence indicates that they are slower than adults One consideraton is that the sensory transmission time from eye to brain is about 20 msec slower for infants than for adults for the type of stimul we used here (Sokol, 1982) The most comparable RT data that do exist were collected from 2-month-olds by Aslın and Salapatek (1975) They reported a median value of $480 \mathrm{msec}$ for a $10^{\circ}$ movement in the situation most comparable to ours Thus, we conclude that a 200 msec boundary is reasonable, though possibly conservative at this age, and that eye movements that occurred proor to this time boundary reflect an eye-movement command that was intuated pror to stimulus onset

The percent of fixation shifts dunng the anticipation interval is shown separately for the early and late groups in Table 1 An eye movement was counted dunng the irregular senes if it occurred in the anticipation interval (up to $200 \mathrm{msec}$ following event onset), even if it was in error ( $1 \mathrm{e}$, the following event did not change location) Combining across the early and late groups, there was a higher shift likelihood for the alternating than for the irregular senes, $22 \%$ versus $111 \%, F(1,10)=$ $45, p=06$ However, an examination of Table 1 suggests that the advantage of the alternating senes occurred only when that senes appeared late, that is, for events $31-60$ Babies in this senes shifted their fixations in the anticipation interval for almost $34 \%$ of all events, reliably more than for their own irregular senes, $t(10)=265, p<05$, or for the alternating early group's alternating, $t(10)=$ $326, p<01$, or irregular senes, $t(10)=359$, $p<01$

Facilitation results - The adult $\mathrm{RT}$ literature suggested that if infants detected the predictability of the alternating sequence and

TABLE 1

Median Reaction times and Percent of anticipations AND FAST, INTERMEDIATE, AND SLOW REACTIONS

\begin{tabular}{|c|c|c|c|c|}
\hline & \multicolumn{4}{|c|}{ Sequence } \\
\hline & \multicolumn{2}{|c|}{ Alternating Early } & \multicolumn{2}{|c|}{ Alternating Late } \\
\hline & Alternating & Irregular & Alternating & Irregular \\
\hline \multicolumn{5}{|l|}{ Reaction times } \\
\hline Baselıne RT (median) & $\begin{array}{c}475 \\
(116)\end{array}$ & & & $\begin{array}{c}462 \\
(126)\end{array}$ \\
\hline Median RT & $\begin{array}{c}409 \\
(67)\end{array}$ & $\begin{array}{c}445 \\
(87)\end{array}$ & $\begin{array}{c}373 \\
(34)\end{array}$ & $\begin{array}{c}478 \\
(110)\end{array}$ \\
\hline \multicolumn{5}{|l|}{ Categones of reaction times (\%) } \\
\hline Fast $(200-300 \mathrm{msec})$ & 278 & 208 & 296 & 204 \\
\hline Intermediate $(300-450 \mathrm{msec})$ & 323 & 332 & 438 & 232 \\
\hline Slow $(>450 \mathrm{msec})$ & 399 & 460 & 266 & 564 \\
\hline Percent of anticipation & 104 & 74 & 337 & 148 \\
\hline
\end{tabular}

Note - Standard deviations are in parentheses 
If they were developing expectations for those events, their speed of response to the onset of each slide would be enhanced Of course, a sensible analysis for this possibility required that anticipatory fixations be excluded Thus, the tme values reported below are taken only for RTs that exceeded $200 \mathrm{msec}$ following event onset RTs in excess of $700 \mathrm{msec}$ were given values of $700 \mathrm{msec}$, the duration of strmulus onset

A baselıne RT (median) was calculated for the first 3-5 alternating events, the specıfic number depending on how many scorable frames were obtaned near the beginning of the senes (Scorable frames varied because infants sometmes falled to look at one or more early events, or their head movement precluded recording of the eye) This baselıne was intended to serve as an individual reference value for RT, presumably before the infant had an opportunity to pick up the spatal and temporal regulanty of the senes

For the early and late groups combined, the postbaseline median RT for the irregular senes was almost identical to the baseline, $462 \mathrm{msec}$ versus $469 \mathrm{msec}$ Thus, there is no indication from this experiment that RT declines with increasing familianty with the expermmental setting or the stumulus events, per se However, the combined postbaseline value for the alternating senes was considerably lower than baseline, 391 msec versus 469 msec, this improvement represents about $29 \%$ of the total possible change, given a lower limit on RT of $200 \mathrm{msec}$ An ANOVA on medians with condition (baseline, alternating postbaseline, and ırregular postbaseline$469 \mathrm{msec}, 391 \mathrm{msec}$, and $462 \mathrm{msec}$, respectuvely) as a within-subject factor, and sequence as a between-subject factor, yielded a significant condition effect, $F(2,20)=391, p$ $<05$ Also, there were sıgnificant individual differences in RT, $F(10,20)=286, p<05$ The alternating-postbaseline median was significantly lower than that for the baseline, $t(20)=253, p<05$, or than that for the Irregular postbaseline, $t(20)=229, p<05$ The slight difference between the irregular postbaseline and the baseline did not approach significance

Analyses were carned out on "fast" and "slow" RTs separately to determine whether RT differences were uniform No analysis was carned out on intermediate times as these were completely determıned by percentages in the other categones An analysis of vanance on the percent of fast postbaseline RTs (between 200-300 msec) produced a sıgnificant type man effect, with a higher percent for the alternating than for the irregular senes, $287 \%$ versus $206 \%$, respectively, $F(1,10)=$ $599, p<05$ These values were quite similar for the two sequence conditions

An analysis of vanance on the percent of slow RTs (longer than $450 \mathrm{msec}$ ) produced a significant main effect of type, $F(1,10)=104$, $p<01$, and a marginally stable type $\times$ sequence interaction, $F(1,10)=454, p=06$ Examination of Table 1 indicates a larger difference between the irregular and altemating senes when the altemating senes appeared late than when it appeared early For the latealternation condition (events 31-60), there was a smaller percent of slow RTs than for the within-subject, irregular-senes companson (events 1-30), $t(10)=379, p<01$, or for the between-subject irregular senes comparison (events 31-60), $t(10)=246, p<05$ A lower percentage of slow movements occurred for the alternating-late condition than for the alternating-early condition group, but the difference was only marginally stable, $t(10)=$ $169,10<p<15$

Other behavior durng the ISIExcluding anticipations, dunng the ISI, babies made only small refixations that did not significantly change the direction of their gaze on $832 \%$ of the events They looked down, up, or farther to the same side during the ISI after $168 \%$ of the events

Two detaled examples of performance in the task-Figure 2 displays the stimulusby-stumulus RT data for two subjects who had different patterns of performance This figure is intended to give the reader a graphic feel for the performance of individual subjects in this task Both subjects received the irregular senes (slides 1-30) pror to the alternating series (slides 31-60) The vertical axis represents reaction tume, and the horizontal axis represents the slide number (shdes 1-60) The horizontal dashed line is drawn at the 200-msec RT boundary that we used to define an anticipatory movement. The open circles represent reactions or anticipations of shdes on the nght side, and the filled circles represent reactions or anticipations to the left side Curcles are connected when they represent adjacent trals Fewer circles appear for the urregular senes, because there were fewer left-right shifts in location (resulting in fewer eye-fixation shifts for which a RT could be measured)

Both subjects had a higher percent of fixation shifts in the anticipation interval dur- 
Child Development
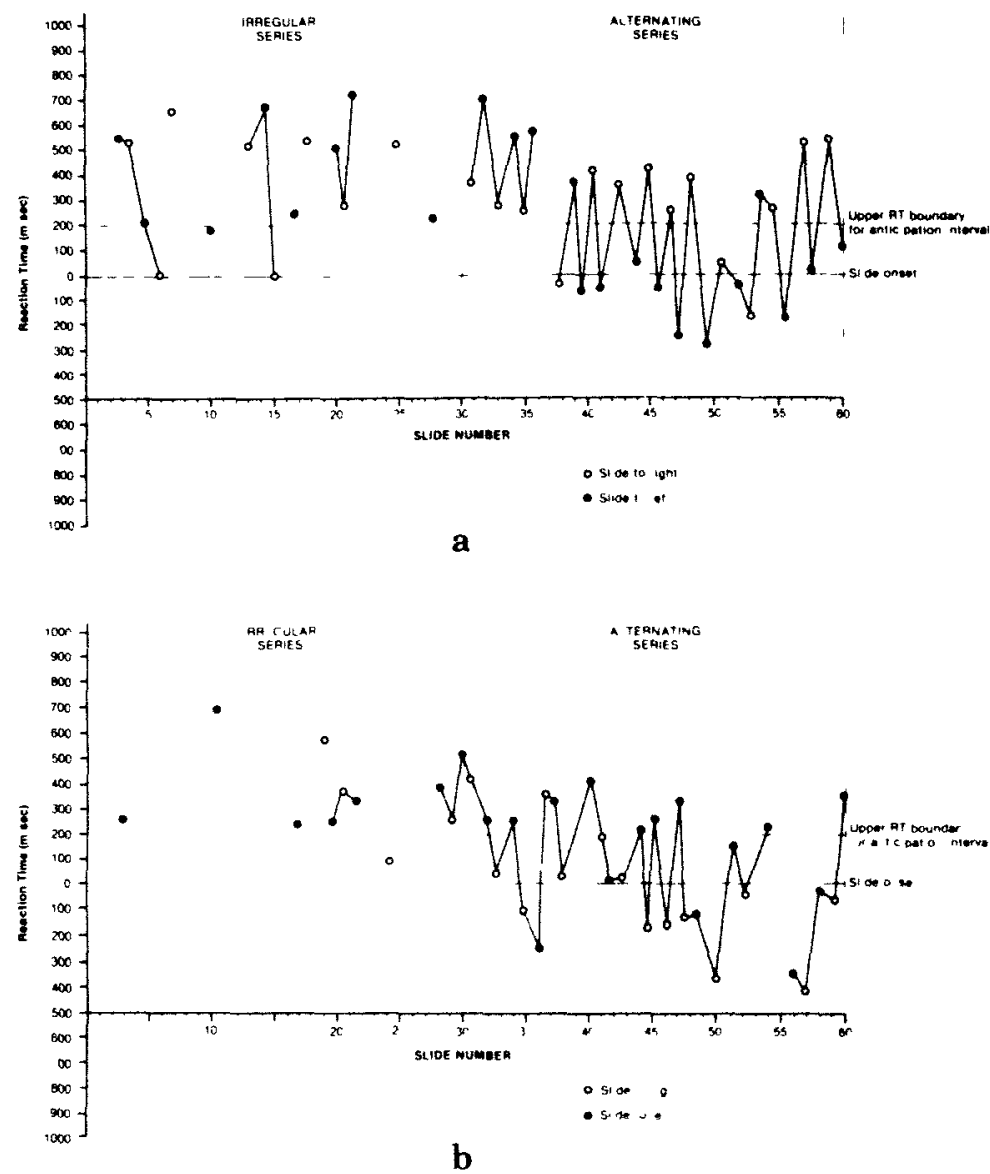

Fig 2 -Plot of reaction times against shde number for the 60-slide senes The data for two subjects are shown (Figs $2 a$ and $2 b$ ), both of whom received the irregular senes first $\mathrm{A}$ vertical dashed line separates the irregular from the regular senes The honzontal dashed line is drawn at the $200-\mathrm{msec}$ boundary that separated what was defined as anticipatory movements from event reactions

ing the alternating than the irregular senes, although some side shiftng occurred in this interval for the irregular senes also The subject shown in Figure $2 a$ displayed many more left-than right-side anticipations, whereas the subject in Figure $2 b$ had a more even side balance in anticipations and near anticipatons The pattern of behavior essentially stabilized for both subjects within about 8-11 slides after the onset of the alternating senes

\section{Discussion}

Infants provided evidence that they can rapidly develop expectations for visual events even when they have no control over those events The evidence consisted of enhanced reaction times and more anticipatory fixations for a senes of events that was predictable as opposed to a senes that was less predictable The term "less predictable" is used ad- visedly In fact, the irregular senes we used was reasonably predictable and therefore provided a very conservative estimate for companson with the altemating series In the $1 \mathrm{r}$ regular senes, events appeared in only one of two places, there was a $50 \%$ probability that the spatal location would change from one event occurrence to the next, and the time of event appearance vaned around a fixed value by only \pm 200 msec Thus, the companson was between one condition that provided a strong base for developing expectations and a second condition that provided a weaker base for developing expectations

Still, the evidence for a faclitation effect was clear from the analyses of both the median RT data and the percent of fast movements This was true for both the alternatingearly and alternating-late conditions (whether the companson for the alternating condition 
was the baseline or the irregular series) Supporting evidence for the presence of expectatons also came from the analyses of percent of visual anticipations and slow fixations, but here the outcomes were complicated somewhat by the supenor performance dunng the alternating senes of those subjects who recelved that senes late (events 31-60) When the alternating senes occurred early (events 1-30), performance was only slightly better for anticipations and slow fixations than for the urregular senes

We believe that performance on the alternatang-late senes was supenor to that of the altemating-early senes because of a "dazzle effect" A baby began this experiment by seeing the room lights darken, followed immediately bv the appearance of little pictures that were colored, changed each second, shifted their location, moved up and aown, and appeared and disappeared It is unlikels that the infant had ever expenenced anything like this before The contnnual and rapid change in the stimulus array may have required some "getting used to" before the baby could attend to the higher-order spatial and temporal regulanties that governed the sequence

In a similar, pnor study (Haith, Hazan, \& Goodman, 1984) ${ }^{2}$ we also found a significant decline in RT from baseline for alternating events Here, we obtanned no evidence that the effect can be attributed to familianty as the median RTs for the irregular series were quite similar whether the senes occurred for events $1-30$ (478 msec) or 31-60 (445 msec) Moreover, these values were within $5 \%$ of the overall median baselıne RT calculated on the first 3-5 events $(469 \mathrm{msec})$ In both the pnor and current study, the facilitation effect is most credibly attributed to infant's detecton of the spatial-temporal predictability in the senes This conclusion is supported by the significantly lower RT for the alternating (predictable) senes in the current study, whether it appeared early or late in the sequence

The anticipation and facilitation phenomena fit naturally into a discussion of perceptual learning but with a somewhat unusual twist The bulk of the developmental literature on perceptual learning concerns identifi- cation and discrimination, with action serving only as an index of the process We see eye movements and sensory recepton as integral and inseparable in the process of visual perception, at least in early infancy This process seems most closely related to the type of correlative feed-forward and error-checking action models that have their roots in Helmholtz's early work and were developed by such people as von Holst (1954), with many additional refinements In bnef, we would argue that, as early as 35 months of age, the baby can create an action-based perceptual model of the situation he or she confronts, can generate short-term expectations from this model, and can support action, sometimes from these expectations (in the extreme case, anticipation), but more tvpicallv in orchestration with sensory input (in the case of facilitatoon) This modeling, expectation, and action sequence serves to maintain continuity in an ever-changing perceptual world where objects and the head frequentlv move continuousl and the eves, discontinuouslv

Several other future-onented, percepton/action systems will unfold within the half year for the 35 -month-old that will facilitate such behaviors as reaching and catching (von Hofsten, 1983) and infant locomotion (Benson, Welch, Campos, \& Harth, 1985) These accomplishments share the component skills of detection of environmental regulanties, $1 \mathrm{~m}$ plementation of controlled action, and prediction of their interrelation It seems likelv that the prnnciples underlving the establishment of the eve-movement prediction svstem are similar to those skills required for these later accomplıshments In a simılar vein, Piaget noted that " this anticipatory function is to be found over and over again at every level of the cognitive mechanisms and at the very heart of the most elementary habits, even of perception" (P1aget, 1971, p 19) From P1agetian theory we might also expect that the early body-centered, future-onented skills will eventuallv give nse to more cognitively based planning skills

We are certain that some will feel that this characterization attributes too much cognitive capability to the infant Perhaps But it is also true that such expectations are realized a few months later (see, e g, Moore, 1896,

\footnotetext{
${ }^{2}$ The present results confirm those of a similar study with nine 35 -month-olds that did not contain complete data from an irregular-senes control condition (paper presented at the ICIS meetings in New York, Apnl 1984) The median RT for post baseline alternatng events uas $327 \mathrm{msec}$, significantly lower $(p<05)$ than the baseline median of $427 \mathrm{msec}$ Fast intermediate and slow reaction times (see Table 1 for definitions) occurred for $411 \% 391 \%$, and $198 \%$ of the nonanticipaton trals Anticipations occurred for $186 \%$ of the altemating events
} 


\section{Child Development}

Praget, 1954, Rupin, 1930) It is unlikely that they anse emergently, as Fischer (1980) has convincıngly argued, skulls appear earhest in those spheres for which the infant has the greatest opportunity for practice There is no voluntary motor system that is better practiced than the oculomotor system, nor is there any other motor system that so closely approximates the mature state in early infancr $B y$ conservatuve estumate, by 35 months of age, a baby has expenenced 800 hours of alert wakefulness (Parmelee, Wenner, \& Schulz, 1964) and dunng those hours has made 3-6 million eye movements That is a lot of practice Further, by this age the infant has encountered untold numbers of occasions of predictable object motion Thus, there is reason to believe that analogues to perceptionaction skalls that emerge later will appear earliest in the sensory, perceptual-motor, and cognitive processes that comprise the visual system

We mentioned earlier the observations of anticipatory behavior by Haith et al (1969), the report by Anglin and Mundy-Castle (1969), and the formal study by Nelson (1968)

For all of these studies, eye movemerits were under observation in a situation for which temporal and spatial rules governed visual sequence of events Only the Nelson study, however, has been published and contains adequate detal for critical evaluation of results relevant to the development of expectatons Nelson presented babies with a senes of sequentally flashing lights in a row Expectations were inferred when eye fixations continued as events were occasionally deleted and also when the eyes moved toward the front of the senes after the last event While the data were suggestive, there was an inadequate baseline of companson with behavior dunng an unpredictable sequence of events, the "anticipation" activities could have reflected a combination of contunuation efforts (as the sequential stmulı moved in a straight line) and center-return tendencies (after the last event on the far side occurred) Our findings indicate that anticipation-like behavior can occur in an irregular senes but is more probable with a regular senes As far as we know, the present evidence for response facilitation in infants has no precedent, although the effect has been well documented in the adult literature (e $\mathrm{g}$, Polidora, Ratoosh, \& Westheimer, 1957, Stark, Vossius, \& Young, 1962, Vaughan, 1983)

There are alternative interpretations to the behavioral phenomena we have observed and, certainly, different ways of thinking about them We shall discuss three of these the effects of familianty, the role of entrainment, and the issue of infant learning The effect of familianty might be raised as an issue in interpreting the stronger evidence for anticipation and facilitation (in fewer slow RTs) for the late- than early-alternation conditon While we believe that familianty can explain the difference between the late- and early-alternation performance (elimination of the "dazzle" effect), it cannot be argued that there is simply an increasing tendency with the passage of time for babies to switch sides in the anticipation interval or to yield faster RTs If this were the case, we should have obtained comparable data for the late-1rregular condition (events 31-60)

The entrainment interpretation of anticipatory and facilitory behavior leans on evidence in the literature that the biological rhythms of babies tend to adjust to the rhythm of the environment One example is the developing sensitivity of infants to a diurnal rhythm around 2 months of age Another example involves thinking of the infant's eyemovement system as a kind of oscillator, dnven by left and nght stimulus "snap shots" We see no way that the entranment interpretation could account for the difference we found between the alternating-early and alternating-late conditions While babies were engaged in the alternating senes in the alternating-early condition (and fixated virtually every event), we saw evidence for expectancies only in the increased proportion of fast RTs (compared to the irregular senes) What is more important, this interpretation implies a regulanty in behavior that we did not observe Infants sometimes, for example, would anticipate several nght events, in sequence, or respond very rapidly to those events, but would respond relatively slowly to left events (see Fig 2) In short, a careful look at our data indicated anything but the kind of lock-step response that, according to this interpretation, should mirror the fixed spatial-temporal sequence we presented

Have we simply provided another illustration of learning in infants? Of course, a $^{2}$ kind of learning must be involved, in the sense that infants acquired information about the spatual and temporal properties of the v1sual sequence The question is whether standard classical or operant learning interpretatons can accommodate the phenomena under analysis Perceptual learning processes have not typically rested easily in these traditions, 
but a specific action was integral to the learnIng examıned here, so the fit might be somewhat better A complete analysis of the applicability of the traditional learning models for our observations would consume more space than is warranted We conclude, however, that they are unlikely to fit well for the following reasons For classical conditioning interpretations (a) although there are exceptions, classical conditioning analyses are typically applied to autonomic rather than skeletal responses, $(b)$ left and nght eye movements did not initally satisfy the fixed relation to the left- and nght-picture onsets that one expects of unconditioned stumulusunconditioned response relations, such as that between an air puff and eye blink The "stimulus-response" tuming was highly vanable, and sometumes the babies did not even fixate the first 2-3 slides, (c) some infants began to anticipate the two side events at the same time, which would seem a remarkable coincidence for two independent classical conditioning tasks, (d) the rapidity with which the skill was acquired in a setting that required two learning connections at once (or one while being distracted by another) flies in the face of the infant leaming literature (Brackbill, Fitzgerald, \& Lintz, 1967, Papousek, 1967) The average number of events on a side after which the first anticipaton was made across all subjects (who had at least one anticipatory response), in both this and our earher expenment was 54 trals on the left side and 55 trials on the nght, that is, within about 16-17 sec of exposure to the alternating senes

An operant analysis shares the coinc1dence problem in $(c)$ above, and the rapidity of learning even one operant response so quickly is so out of line with the operant literature (see Olson \& Sherman, 1983, Sameroff \& Cavanaugh, 1979) that the problem of modeling the learning of two operants simultaneously seems beyond credibility It is also important to remember that, in contrast to operant paradigms, the senes proceeded independently of the infant's responses Further, it would be difficult to argue that our procedure increased the likelihood of directionally appropnate responses, as required by an operant analysis, since the tendency to fixate a peripheral stimulus onset is strong even at birth (Harris \& MacFarlane, 1974) Finally, neither model accommodates the facilitation effect that we observed

Our data demonstrate that babies as young as 35 months of age can rapidly detect spatal and temporal regulanties that govern a visual sequence, develop expectations for the impending event in the series, and use those expectations to support adaptive action either in the absence of visual input (anticipation) or in orchestration with it (facilitation) However, we feel that an important point would be missed if these abilities were seen merely as additions to a taxonomic collection of infant perceptual skills We believe it is important to ask why a baby would gratuitously develop expectations for a senes of events over which it has no control Why not simply respond on an ad hoc basis to each picture onset? We believe that infants are motivated to detect regulanties in dynamic events and to develop expectations partly in order to bring their behavior under self-control, the alternative is to let their behavior be enslaved to external events, which, at least for the adult, requires substantally more effort Thus, in addition to demonstrating the young infant's abilities to detect regulanty, to develop expectations, and to govern adaptive action based on expectathons, these findings suggest a natural motivaton in babies at a very early age to control their own perceptual activity

Apart from the interpretation of our results, the paradigm we have developed provides a window on the fast-paced and shortlived expectations that young infants generate for dealing with their dynamic visual world This paradigm generates many data points that are gathered quickly in a task that engages the infant, and data reduction is straightforward and relatively nontechnical However, we do not want to claim that we have seen merely the thp of the cognituve iceberg or to endow the infant of 35 months with excessive capacity for dealing with future events Rather, we believe that we have approximated an optimal situation for tapping into the expectation phenomenon-by employing highly interesting events, a highly skilled motor system, and temporal, spatal, and contungency parameters that demand as little of the baby as possible And we want to alert potential researchers in this area to the fact that this convergence of factors was not casually chosen In one form or another, one of $\mathbf{u s}(\mathrm{M} \mathrm{M} \mathrm{H})$ has worked on this problem for over 20 years The present paradigm is a distillation of many failures and partial successes How far such factors as the time and spatal parameters can be pushed without destroying the phenomena is open to question More interesting is how complications of the temporal and spatial contngencies will affect 
performance In part, these are questions not only about the paradigm but also about the cognitive complexity the infant possesses in the domain of expectations Most certanly, these are developmental questions that also hold promise for exploning individual differences in cognitive status

Given the fact that expectations occups core status in cognitive theones, it is clear that a complete exposition of cognitive development requires an understanding of the earliest phases of future-onented behavior The paradigm and results we have described provide a tool and a beginning for this understanding

\section{References}

Anglin, J, \& Mund -Castle, A C (1969 Apnl) The development of looking in infancy Paper presented at the meetings of the Societ for Research in Child Development, Santa Monica, CA

Aslin, R N (1981) Development of smooth pursuit in human infants In D F Fisher, $\mathrm{R} A$ Mont, \& $\mathrm{E} J$ Senders (Eds), Eye mocements Cognition and usual perception (pp 31-51) Hillsdale, NJ Erlbaum

Ashn, R N , \& Salapatek, P (1975) Saccadic localızation of penpheral targets by the very young human infant Perception and Psychophysics 17, 293-302

Becker, W (1972) The control of eye movements in the saccadic system Bibliotheca Ophthalmologica, 82, 233-243

Benson, J B, Welch, L, Campos, J J , \& Hatth, M M (1985, July) The development of craul. ing in infancy Paper presented at the meetungs of the Intemational Society for the Study of Behavioral Development, Tours, France

Biederman, I, Glass, + L, \& Stacy, E W, Jr (1973) Searching for objects in real-world scenes Journal of Experimental Psychology, 97, 22-27

Brackbill, Y, Fitzgerald, H E, : Lintz, L M (1967) A developmental studv of classical conditoning Monographs of the Society for Research in Child Development, 32(8, Senal No 116)

Fischer, K. W (1980) A theory of cognitive development The control and construction of hierarchies of skalls Psychological Review, 87, 477-531

Fredman, A (1979) Framing pictures The role of default knowledge in automized encoding and memory for gist. Joumal of Experimental Psy. chology General, 108, 316-355

Goodman, G S (1980) Picture memory How the action schema affects retention Cognitive Psychology, 12, 473-495

Goodman G S, Pnce, D W, Cohen, K, \& Hatth, M M (1981, August) What you see is what you get Scanning action scenes Paper presented at meetings of the Amencan Psychological Association, Los Angeles

Hath M Y Hazan, C, \& Goodman, G (1984) Infants expectation and anticipation of future usual events Infant Behavior and Development, 7, 154 (Abstract)

Hath II M Kessen, W, \& Collins D (1969) Response of the human infant to level of complexit of intermittent wsual movement Joumal of Experimental Child Psychologu, 7, 52-69

Harrs, P \& VacFarlane, 4 (1974) The growth of the effective usual held trom birth to seven weeks Journal of Expenmental Child Psychol. ogy $18,340-348$

Hebb, D O (1949) Organization of behat tor New York Wilev

Helmholt $H$ von (1925) Treatse on physıological optics (Vol 3, 3d Ed, Ed and trans P C Southall) Menasha, Wl Optical Societv of Amenca

Hofsten, C von (1983) Catching skills in infancy Joumal of Expenmental Psychology Human Perception and Performance, 9, 75-85

Holst, E von (1954) Relations between the central nervous system and the penpheral organs Brttsh Journal of Antmal Behaviour, 2, 89-94

Kagan, J (1970) Attention and psvchologeal change in the young child Scrence, 170, 826-832

Markman, $H$ (1981) The prediction of mantal distress A five-vedr followup Journal of Consulting Psychology, 49, 760-762

Minskv, $M$ A (1975) A framework for representing knowledge In P H Winston (Ed) The psychology of computer usion (pp 211277) New York McGraw-Hull

Moore, K C (1896) The mental development of a child Psychological Revieu Monograph Supplement (1, No 3$)$

Nelson, K (1968) Organization of visual-tracking responses in human infants Jourmal of Expermental Child Psychology, 6, 194-201

Olson, G M \& Sherman, T (1983) Attention, learning and memory in infants In $M$ Hatth \& J J Campos (Eds), P H Mussen (Senes Ed), Handbook of child psychology Vol 2 Infancy and developmental psychobiology (pp 1001-1080) New York Wiley

Papousek, H (1967) Expenmental studies of appetitional behavior in human newborns and infants In $\mathrm{H}$ W Stevenson, $\mathrm{E} \mathrm{H}$ Hess, \& $\mathrm{H} \mathrm{R}$ Rheingold (Eds), Early behavior Comparative and developmental approaches (pp 249277) New York Wiley

Parmelee, A H Wenner, W H, \& Schulz, H R 
(1964) Infant sleep patterns from birth to 16 weeks of age Joumal of Pediatrics, 65, 576582

Piaget, J (1954) The construction of reality in the child New York Basic

Praget, J (1971) Biology and knowledge Chicdgo University of Chicago Press

Polıdora, V J, Ratoosh, P, \& Westheimer, G (1957) Precision of rhythmic responses of the oculomotor system Perceptual and Motor Skills, 7, 247-250

Ripin, R (1930) A study of the infant s feeding reactions dunng the first six months of life Archives of Psychology, No 116

Sameroff, A J , \& Calanaugh, P J (1979) Learning in infancy A developmental perspective In J D Osofsky (Ed) Handbook of infant development (pp 344-392) New York Wiley
Saslow, M G (1967) Effects of components of displacement-step stmul 1 upon latency for saccadic eye movement Journal of the Optrcal Socrety of America, 57, 1024-1029

Schank, R C, \& Abelson, R P (1977) Scripts, plans, goals and understanding Hillsdale, NJ Erlbaum

Sokol, S (1982) Infart visual development Evoked potential estmates Annals of the Neu rork Academy of Scrences, 338, 514-525

Stark, L, Vossius, G, \& Young, L R (1962) Predictive control of eye tracking movements IRE Transactions on Human Factors in Electrontcs, 3(2), 52-57

Vaughan, J (1983) Saccadic reaction time and visual search In K Raynor (Ed), Eye movements in reading Perceptual and language processes (pp 397-411) New York Academic Press 
This document is a scanned copy of a printed document. No warranty is given about the accuracy of the copy. Users should refer to the original published version of the material. 